\title{
PENGEMBANGAN KOLEKSI JURNAL ELEKTRONIK DI PUSAT LAYANAN PUSTAKA UNIVERSITAS TERBUKA (PUSLATA UT)
}

\author{
M. Arif Baharuddin ${ }^{1 *}$; Margareta Aulia Rachman ${ }^{2}$ \\ ${ }^{1,2}$ Fakultas Ilmu Pengetahuan Budaya - Universitas Indonesia \\ "Korespondensi: marifbaharuddin@gmail.com
}

Diajukan: 9 Mei 2016; Direview: 16 November 2016; Diterima: 24 Maret 2017; Direvisi: 1 April 2017

\begin{abstract}
This research aims to see the development of the electronic journal collection at Puslata UT. This research used qualitative approach with descriptive method. Reviews these results indicate that Puslata UT has run a series of activities for the development of the electronic journal collection, but in fact the use of electronic journals by the academic society is very low. It happened because some temporary policies were not maximized and less inappropriate to fulfill information needs of academic society. Electronic journal more needed for the accreditation process and the study by researcher at UT center. The results of this research shows that PUSLATAUT should make a written policy or guidelines of the development of the electronic journal collection, and create a strategic plan so that electronic journals can reach some academic societies in some areas.
\end{abstract}

\begin{abstract}
ABSTRAK
Penelitian bertujuan untuk mengetahui efektivitas pengembangan koleksi jurnal elektronik di Puslata UT menggunakan pendekatan penelitian kualitatif dengan metode deskriptif. Hasil penelitian menunjukkan bahwa Puslata UT telah menjalankan beberapa rangkaian kegiatan dalam pengembangan koleksi jurnal elektronik, akan tetapi penggunaan jurnal elektronik oleh sivitas akademika UT sangat rendah. Hal ini terjadi karena jurnal elektronik lebih dibutuhkan untuk proses akreditasi dan penelitian oleh peneliti di lingkungan kampus UT pusat. Selain itu, belum memadainya sarana dan prasarana untuk mengakses jurnal elektronik juga menjadi masalah bagi mahasiswa yang mengikuti perkuliahan jarak jauh di beberapa daerah. Berdasarkan hasil penelitian ini, Puslata UT disarankan untuk membuat rencana strategis dan kebijakan tertulis atau pedoman yang mengatur tentang pengembangan koleksi jurnal elektronik agar penggunaan jurnal elektronik dapat menjangkau sivitas akademika di beberapa daerah.
\end{abstract}

Keywords: Collection development; Electronic journal; Academic library; Open education; E-journal

\section{PENDAHULUAN}

Francis K. W. Drury menyatakan bahwa memilih sumber informasi berarti menyediakan sumber informasi yang tepat untuk pembaca yang tepat pada waktu yang tepat (Johnson, 2009). Pernyataan tersebut menegaskan perlunya pertimbangan tentang kebutuhan pemustaka dan waktu dalam menentukan sumber informasi di perpustakaan. Waktu yang tepat dalam pernyataan Drury dapat memiliki dua makna, yaitu pemustaka mendapatkan sumber informasi dengan cepat dan pemustaka mendapatkan sumber informasi yang umur informasinya relevan dengan perkembangan pengetahuan. Salah satu upaya untuk menyediakan sumber informasi yang cepat, aktual, dan sesuai kebutuhan pemustaka adalah menyediakan jurnal elektronik. Kemudahan serta kecepatan mendapatkan sumber informasi ilmiah terbaru merupakan keunggulan jurnal elektronik. Format jurnal elektronik yang dapat didistribusikan 
lewat jaringan elektronik akan memudahkan perpustakaan untuk menyampaikan informasi ilmiah terbaru kepada pengguna kapanpun dan dimanapun secara cepat.

Universitas Terbuka (UT) merupakan salah satu perguruan tinggi di Indonesia yang telah menyadari peran perpustakaan untuk mencapai Tridharma Perguruan Tinggi dengan penyediaan informasinya. Unit Perpustakaan UT adalah Pusat Layanan Pustaka Universitas Terbuka (Puslata UT). Mengingat UT menerapkan sistem belajar jarak jauh dan terbuka dengan pengertian pembelajaran tidak dilakukan secara tatap muka, Puslata UT tidak dapat mengandalkan penyediaan sumber informasi hanya di rak-rak buku. Banyaknya peserta didik yang tersebar di beberapa daerah maka dalam menyediakan sumber informasi yang mudah diakses di manapun dan kapanpun menjadi pertimbangan utama. Menyadari pentingnya informasi yang tepat, untuk pembaca yang tepat, dan pada waktu yang tepat maka Puslata UT telah memanfaatkan perkembangan Teknologi Informasi dan Komunikasi (TIK) dalam penyediaan informasi yang relevan dengan kebutuhan pemustaka, antara lain jurnal elektronik.

Jurnal elektronik berkembang cepat seiring dengan pertumbuhan teknologi informasi dan komunikasi. Akses untuk mendapatkan jurnal elektronik menjadi sangat mudah, cepat, dan dapat dilakukan di mana saja. Kegiatan pengembangan koleksi sangat berhubungan berkaitan dengan perencanaan kebijakan pengembangan koleksi yang terkait dengan anggaran, wewenang, dan alat bantu seleksi bahan perpustakaan yang relevan. Akan tetapi dapat mengecewakan bila jurnal elektronik yang mudah diakses tersebut ternyata berisi informasi yang secara kualitas tidak dapat memenuhi kebutuhan pengguna informasi. Oleh karena itu, Puslata UT harus melakukan kegiatan yang mampu mengarahkan agar koleksi jurnal elektronik dapat didayagunakan oleh sivitas akademika secara maksimal dan optimal untuk memenuhi kebutuhannya. Dalam hal ini, dibutuhkan manajemen pengembangan jurnal elektronik yang mampu mengontrol atau menentukan proses pengembangan jurnal elektronik. Berdasarkan hal tersebut, kegiatan pengembangan koleksi jurnal elektronik di Puslata UT menarik untuk dikaji. Tujuan kajian ini untuk mengidentifikasi masalah pada pengembangan koleksi jurnal elektronik di Puslata UT dalam upaya memenuhi kebutuhan informasi sivitas akademika.

\section{TINJAUAN PUSTAKA}

\subsection{Perpustakaan Perguruan Tinggi}

Definisi perpustakaan perguruan tinggi menurut Moedjono (1979) adalah suatu unit kerja yang merupakan bagian integral dari suatu lembaga perguruan tinggi induknya yang bersama-sama dengan unit kerja bagian lainnya yang berbeda dalam peranannya, bertugas membantu perguruan tinggi yang bersangkutan dalam melaksanakan program Tridharma. Selanjutnya, dalam Standar Nasional Perpustakaan Perguruan Tinggi (2011) disebutkan perpustakaan perguruan tinggi bertujuan menyediakan materi perpustakaan dan akses informasi bagi pengguna untuk kepentingan pendidikan, penelitian, dan pengabdian kepada masyarakat. Tujuan tersebut mengarahkan kegiatan perpustakaan perguruan tinggi pada penyediaan pelayanan informasi untuk mendukung dan melengkapi program belajar mengajar pada seluruh lapisan tingkat pendidikan yang ada di perguruan tinggi.

\subsection{Jurnal Elektronik}

Tidak ada standar yang pasti atas definisi jurnal elektronik karena istilah jurnal elektronik mengacu pada hal yang luas dan beragam serta banyak tipe terbitan yang sudah atau akan tersedia nantinya dalam bentuk elektronik (Nisonger, 1997). Berdasarkan pernyataan itu, sebaiknya dalam mendefinisikan jurnal elektronik jangan terlalu spesifik 
dengan membatasi cara pengolahan, penggunaan, dan penyebarannya karena akan berubah seiring perkembangan teknologi informasi. Definisi jurnal elektronik yang dipakai penulis dalam penelitian ini adalah publikasi berkala atau jurnal yang tersedia dalam format digital (Johnson, 2009).

Pesatnya perkembangan teknologi informasi dan komunikasi mengakibatkan munculnya jurnal elektronik dengan berbagai format dokumen dan cara penyebarannya. Jurnal elektronik pada awalnya diterbitkan dalam format teks ASCII, bitmaps, LaTEX, PostScript, PDF, SGML, dan HTML (Wusteman, 1996). Saat ini, kebanyakan jurnal elektronik diterbitkan dalam HTML dan format PDF, namun ada juga yang menyediakan satu tampilan dari dua format itu. Sebagian kecil memublikasikannya dalam format DOC dan beberapa jurnal juga mulai menyebarkan jurnal elektronik dengan format pendukung audio (MP3). Selain memengaruhi format jurnal elektronik, perkembangan teknologi juga berpengaruh pada cara penyebarannya. Menurut Dhingra (2007), kemungkinan adanya cara penyebaran yang lebih baik akan selalu ada, namun ada beberapa cara penyebaran jurnal elektronik antara lain:

1) Remote access, penyebaran jurnal elektronik ini disediakan oleh penyedia jurnal elektronik di situs web penyedia. Apabila perpustakaan memutuskan untuk berlangganan maka perpustakaan diberi hak akses melalui cara berikut.

a) Akun dan password, pelanggan akan mendapat akun dan password untuk dapat mengakses jurnal elektronik;

b) Intranet, penyedia akan mengenali dan memvalidasi alamat IP server intranet pelanggan;

c) Gabungan, beberapa penyedia menawarkan kombinasi dari kedua cara tersebut di atas.

2) On site access, perpustakaan menyimpan sendiri jurnal elektronik yang hak penyimpanannya diberikan oleh penyedia, biasanya penyimpanan ini menggunakan CD-ROM ataupun mengunggah di situs web perpustakaan.

3) Akses melalui pangkalan data, penyedia jurnal elektronik menyediakan banyak artikel dari beberapa tahun terbit dalam pangkalan data. Melalui pangkalan data, pengguna dapat menemukan dengan mudah artikel yang relevan.

\subsection{Pengembangan Koleksi Jurnal Elektronik}

Meskipun format jurnal elektronik berbeda dengan format buku atau koleksi tercetak lainnya, sebagian besar fungsi kegiatan pengembangan koleksi konvensional dapat diaplikasikan dalam pengembangan koleksi jurnal elektronik (Nisonger, 1997). Hal ini didukung juga oleh Koontz (2010) yang menganggap koleksi digital memiliki banyak kesamaan kriteria dengan koleksi konvensional sehingga harus sesuai dengan ruang lingkup koleksi, permintaan, dan tingkat penggunaan pemustaka serta adanya pengawasan atau evaluasi secara teratur. Pengembangan koleksi, baik yang elektronik maupun konvensional di perpustakaan perguruan tinggi tidak boleh kaku dan harus mampu beradaptasi dengan perkembangan zaman demi penyediaan informasi menuju kepuasan pemustaka. Adapun pengembangan koleksi menurut Direktorat Jenderal Pendidikan Tinggi (2004) meliputi rangkaian kegiatan sebagai berikut. 
1) Menentukan kebijakan umum pengembangan koleksi berdasarkan identifikasi kebutuhan pengguna. Kebijakan ini disusun bersama oleh sebuah tim yang dibentuk dengan keputusan rektor dan anggotanya yang terdiri atas unsur perpustakaan, fakultas atau jurusan, dan unit lain.

2) Menentukan kewenangan, tugas, dan tanggung jawab semua unsur yang terlibat dalam pengembangan koleksi.

3) Mengidentifikasi kebutuhan akan informasi dari semua anggota sivitas akademika yang dilayani. Hal ini dapat dilakukan dengan cara, antara lain:

a) mempelajari kurikulum setiap program studi;

b) memberi kesempatan sivitas akademika untuk memberikan usulan melalui berbagai media komunikasi, dan;

c) menyediakan formulir usulan pengadaan buku, baik secara tercetak maupun maya;

4) Memilih dan mengadakan pustaka lewat pembelian, tukar-menukar, hadiah/sumbangan, dan penerbitan sendiri.

5) Merawat bahan pustaka.

6) Menyiangi koleksi.

7) Mengevaluasi.

Rangkaian kegiatan pengembangan koleksi di atas menunjukkan adanya keterkaitan antara beberapa elemen sivitas akademika dan beberapa pihak di luar sivitas akademika. Berdasarkan rangkaian kegiatan tersebut pula, pengembangan koleksi dapat dijabarkan sebagai rangkaian kegiatan antara kegiatan analisis pengguna, pembagian wewenang dalam usaha pengembangan koleksi, kegiatan penyeleksian koleksi, pengadaan koleksi, deseleksi (penyiangan), dan evaluasi.

\subsubsection{Analisis Pengguna}

Langkah awal dalam menentukan koleksi yang akan dikembangkan adalah menganalisis kebutuhan pemustaka. Kewajiban perpustakaan melayani kebutuhan informasi pemustaka membuat perpustakaan perguruan tinggi perlu untuk mengkaji atau mengenali sivitas akademika. Cara yang paling umum untuk menganalisis kebutuhan pengguna adalah dengan observasi, mendengarkan atau wawancara, dan dokumentasi (Disher, 2007). Observasi penting untuk mengetahui topik yang sedang berkembang dilingkungan perguruan tinggi. Mendengarkan berfungsi untuk menerima informasi secara langsung dari pemustaka dan caranya dapat dilakukan melalui wawancara atau menggunakan kuisioner. Selanjutnya, dokumentasi bertujuan menganalisis data statistik yang kemudian akan digunakan untuk membuat usulan koleksi.

\subsubsection{Wewenang}

Kewenangan merumuskan jalannya pengembangan koleksi menurut Direktorat Jenderal Pendidikan Tinggi (2004) dipercayakan kepada: pustakawan, wakil sivitas akademika, serta wakil unit penelitian dan unit lain yang terkait. Selain merumuskan pengembangan koleksi, beberapa pihak tersebut juga berpotensi untuk menjadi tim seleksi terhadap usulan pengadaan koleksi. Anggota tim seleksi harus memiliki kompetensi yang saling melengkapi antar-anggota dan mampu mempertimbangkan sumber informasi yang terbaik berdasarkan kriteria penyeleksian koleksi. Setelah usulan pengadaan koleksi lolos melewati 
pertimbangan tim seleksi, hasil seleksi diserahkan kepada kepala perpustakaan untuk ditetapkan pengadaannya.

\subsubsection{Seleksi Koleksi}

Kegiatan seleksi koleksi tidak terlepas dari kegiatan analisis pengguna. Menurut Pollet (1982), faktor yang paling penting dalam kegiatan menyeleksi adalah penyeleksi merupakan orang yang profesional dan dengan pengetahuannya mempertimbangkan suatu koleksi layak dijadikan koleksi perpustakaan. Setelah penyeleksi mempertimbangkan koleksi, kemudian menentukan prioritas koleksi yang akan diadakan menurut kriteria sebagai berikut (Disher, 2007).

1) Subjek. Koleksi tentang subjek tertentu yang benar-benar dibutuhkan oleh perpustakaan perguruan tinggi.

2) Permintaan dan potensi keterpakaian. Perpustakaan harus menampung semua masukan dari pemakai, termasuk menampung masukan untuk penambahan koleksi. Masukan dari pemakai tidak semuanya akan dipenuhi karena ada kemungkinan koleksi yang disarankan tidak memiliki nilai pakai berjangka panjang.

3) Kualitas bahan koleksi. Perpustakaan tentunya tidak mau membeli koleksi yang mudah rusak, tidak bisa dipakai lagi, dan tidak bisa terpakai oleh pemakai.

4) Keseimbangan koleksi. Penting bagi perpustakaan perguruan tinggi untuk mempertimbangkan keseimbangan antarsubjek koleksi, baik secara kuantitas maupun kualitas serta jumlah pemakai potensial.

5) Pertimbangan lainnya adalah pengarang, penyedia, format, timbangan buku, harga, sasaran audiensi, tanggal, dan bahasa.

\subsubsection{Pengadaan}

Pengadaan buku untuk koleksi perpustakaan perguruan tinggi berdasarkan pedoman yang tertuang dalam buku "Perpustakaan Perguruan Tinggi: Buku Pedoman" yang diterbitkan oleh Direktorat Jenderal Pendidikan Tinggi tahun 2004, dapat dilakukan melalui beberapa cara.

1) Pembelian dan Pelangganan

Pembelian koleksi memungkinkan perpustakaan mendapatkan materi koleksi yang sesuai dengan kebutuhan perpustakaan perguruan tinggi. Dalam hal pembelian jurnal elektronik menurut King dan Tenopir (2004), dapat dilakukan melalui:

a) Individual subscription, yaitu pembelian satu judul jurnal elektronik dari agen secara berlangganan.

b) Publishers packages, yaitu merupakan kumpulan jurnal dari satu penerbit.

c) Aggregator journal, yaitu merupakan vendor yang menyediakan akses ke berbagai penerbit jurnal. Aggregator tidak memiliki atau mengunggah konten, hanya merambah konten lewat pencarian.

d) Full-text database journals, yaitu menyediakan akses ke jurnal elektronik dari beberapa penerbit, tetapi judul ditambahkan atau dihapus secara berkala sesuai dengan kontrak dengan penerbit. 
2) Pertukaran

Adanya tukar-menukar terbitan memungkinkan perpustakaan mendapatkan koleksi yang sulit diperoleh. Dengan adanya pertukaran akan memberi peluang untuk mengembangkan atau menguatkan kerja sama antar-perpustakaan.

3) Hadiah atau gratis

Perpustakaan memperoleh bahan perpustakaan, baik dari perorangan, lembaga pemerintah, maupun swasta secara gratis yang diberikan oleh penyumbang secara langsung ataupun mengajukan permintaan sumbangan.

4) Terbitan perguruan tinggi

Perpustakaaan perguruan tinggi hendaknya menghimpun semua bahan perpustakaan yang diterbitkan oleh lembaga yang bersangkutan, meliputi koleksi lokal dan literatur kelabu. Hal ini penting karena koleksi lokal dan literatur kelabu tidak beredar bebas di pasaran dan penggunaannya merupakan bagian dari penyebaran informasi dalam melaksanakan Tridharma Perguruan Tinggi. Dalam Buku Pedoman Pembinaan Koleksi Perpustakaan Perguruan Tinggi (1999), terbitan perguruan tinggi meliputi:

a) Penerbitan dari lembaga induk tempat perpustakaan berada.

- Perpustakaan hendaknya dijadikan pusat penyimpanan semua penerbitan lembaga di perguruan tingginya.

- Perpustakaan dapat ditunjuk sebagai penyalur dari semua penerbitan lembaga yang bersangkutan.

b) Penerbitan oleh perpustakaan sendiri, seperti daftar tambahan koleksi, buletin, manual, dan bibliografi.

5) Titipan

Perpustakaan berhak memanfaatkan koleksi dengan syarat merawat dan mengawasi penggunaannya. Dengan adanya perolehan koleksi melalui titipan, perpustakaan tidak perlu menganggarkan dana untuk membeli koleksi.

\subsubsection{Penyiangan}

Penyiangan (weeding) koleksi jurnal elektronik dengan penyiangan koleksi tercetak, misalnya keputusan untuk tidak lagi menyediakan akses melalui gropher atau website dan mengarsipkan jurnal elektronik secara lokal (Nisonger, 1997). Beberapa pertimbangan dalam penyiangan pada koleksi jurnal elektronik, seperti kebutuhan untuk menghemat ruang penyimpanan atau disk dan biaya, nilai isi jurnal out of date maupun nilai informasi pada jurnal yang memiliki kemanfaatan jangka panjang sehingga lebih baik disimpan secara lokal. Alasan penyimpanan jurnal elektronik secara lokal karena memiliki nilai informasi jangka panjang. Pendapat ini juga didukung oleh Pendit (2008) yang menyatakan "secara filosofis, semua sumber daya yang mengandung nilai kultur dan intelektual dari masa lampau harus tersimpan dengan baik sehingga di masa kini dan mendatang kita selalu dapat melacak kembali apa saja yang sudah dikerjakan, dipikirkan, didiskusikan oleh sebuah masyarakat khususnya, atau sesama umat manusia pada umumnya". 


\subsubsection{Evaluasi koleksi}

Perpustakaan perguruan tinggi perlu mengadakan kegiatan evaluasi koleksi untuk menilai daya guna dan hasil guna koleksi dalam memenuhi kebutuhan sivitas akademika serta program perguruan tinggi. Evaluasi koleksi juga bermanfaat untuk merencanakan pengadaan, anggaran, dan perawatan. Kegiatan evaluasi tersebut perlu diadakan secara teratur agar koleksi perpustakaan sesuai dengan perubahan dan perkembangan pengetahuan. Tujuan kegiatan evaluasi menurut Direktorat Jenderal Pendidikan Tinggi (2004) sebagai berikut:

a) mengetahui mutu, lingkup, dan kedalaman koleksi;

b) menyesuaikan koleksi dengan tujuan dan program perguruan tinggi;

c) mengikuti perubahan, perkembangan, sosial budaya, ilmu dan teknologi;

d) meningkatkan nilai informasi;

e) mengetahui kelemahan dan kekuatan koleksi;

f) menyesuaikan kebijakan penyiangan koleksi.

Terdapat dua pendekatan yang biasa digunakan dalam mengevaluasi koleksi. Pendekatan pertama, yaitu analisis koleksi berfokuskan pengguna, yang kegiatannya mengukur keterpakaian koleksi oleh pengguna atau seberapa baik kebutuhan pengguna terpenuhi. Contoh pendekatan yang berfokuskan pada pengguna adalah kajian sirkulasi, statistik pinjam antar-perpustakaan, statistik permintaan pemakai, dan berbagai kajian pemakai, seperti lama pengguna dalam proses mendapatkan informasi. Adapun pendekatan kedua, yaitu analisis yang berfokuskan pada koleksi, yang kegiatannya mengukur tingkat kedalaman koleksi atau bagian dari suatu koleksi. Contoh pendekatan yang berfokuskan pada koleksi adalah checklist, kajian ketersediaan rak, serta penerapan standar dan evaluasi dari pakar.

\section{METODE}

Penelitian ini bertujuan mengidentifikasi berbagai hal yang perlu dipertimbangkan oleh Puslata UT dalam mengembangkan koleksi jurnal elektronik. Penelitian ini menggunakan pendekatan kualitatif menggunakan metode deskriptif. Metode deskriptif dipilih untuk mencari deskripsi yang tepat dari semua keadaan yang berkaitan dengan kegiatan pengembangan koleksi jurnal elektronik di Puslata UT.

Menurut Nawawi (1992), penelitian dengan metode deskriptif adalah penelitian yang bertujuan untuk mengidentikasi masalah dengan memaparkan keadaan objek yang diselidiki sebagaimana adanya dan berdasarkan fakta-fakta aktual. Dalam penelitian ini, penulis menggunakan teknik pengumpulan data berupa wawancara, observasi, dan studi dokumen. Informan yang diwawancara pada penelitian ini dipilih berdasarkan purposive sampling. Adapun kriteria dari informan adalah pihak yang telah paham betul tentang pengembangan koleksi jurnal elektronik di Puslata UT, dan pihak profesional atau yang mengetahui, baik tentang jurnal maupun penyedianya. Selain itu, kriteria yang paling penting untuk dijadikan informan adalah pihak yang mengetahui latar belakang sivitas akademika UT dan kebutuhannya. Berdasarkan kriteria-kriteria tersebut, penulis menentukan pihak yang menjadi informan sebagai berikut.

1) Unsur pimpinan Puslata UT yang berhubungan dengan aspek manajerial;

2) Penanggung jawab kegiatan pengembangan koleksi jurnal elektronik; 
3) Pihak penentu kebijakan yang memiliki kewenangan dalam menentukan koleksi jurnal elektronik sebagai perwakilan dari sivitas akademika.

Tabel 1 menunjukkan daftar informan yang namanya disamarkan.

Tabel 1. Informan Penelitian

\begin{tabular}{|c|c|c|c|}
\hline Nama & $\begin{array}{c}\text { Jenis } \\
\text { Kelamin }\end{array}$ & Tingkat Pendidikan & Jabatan \\
\hline Informan 1 & Laki-laki & S3 Ilmu Sejarah & Kepala Perpustakaan \\
\hline Informan 2 & Laki-laki & S2 Ilmu Perpustakaan & Kepala Bidang Pengadaan \\
\hline Informan 1 & Perempuan & S3 Kimia Lingkungan & Kepala Program Studi \\
\hline
\end{tabular}

\section{HASIL DAN PEMBAHASAN}

\subsection{Pengembangan Koleksi Jurnal Elektronik di Puslata UT}

Jurnal elektronik yang disediakan Puslata UT merupakan salah satu sumber informasi yang akses dapat dilakukan oleh sivitas akademika UT yang tersebar di beberapa daerah. Perkembangan teknologi informasi dan komunikasi memberikan peningkatan fungsi Puslata UT yang dulunya hanya melayani penulis modul dan sivitas akademika di sekitar kampus UT, Kini Puslata UT dapat memberikan layanan jurnal elektronik kepada sivitas akademika secara lebih luas dan mudah. Cara mengakses jurnal elektronik dilakukan melalui tiga cara akses, yaitu: 1) mengunjungi langsung gedung Puslata UT; 2) akses melalui intranet bagi sivitas yang berada di kawasan kampus UT; dan 3) akses melalui internet.

Puslata UT menyediakan jurnal elektronik dengan berbagai format, antara lain PDF, HTML, JPG, dan format lain yang mendukung audio serta audio-visual. Selain itu, penyedia jurnal elektronik yang dilanggan Puslata UT menyediakan beberapa fitur yang memungkinkan untuk berbagi artikel, mengirim artikel langsung ke surel (email), langsung melakukan pencetakan (print), dan fitur lainnya. Keunggulan jurnal elektronik yang dilanggan Puslata UT sebagai salah satu media untuk melayani kebutuhan informasi sivitas akademika tentunya tidak akan bermanfaat bila keberadaannya tidak dikenal ataupun dipahami cara penggunaanya. Oleh karena itu, Puslata UT melakukan beberapa upaya agar jurnal elektronik dimanfaatkan secara optimal oleh sivitas akademika, meliputi:

- Promosi melalui surel bahwa Puslata UT telah melanggan dan menyediakan akses ke pangkalan data jurnal elektronik. Promosi ini juga merupakan sarana bagi Puslata UT dalam menyampaikan username dan password untuk mengakses beberapa pangkalan data berbayar yang sudah dilanggan. Username dan password yang diberikan kepada sivitas akademika semuanya seragam karena Puslata UT melanggannya berupa akun multiuser dan unlimited user dengan pertimbangan lebih efisien dan membuka peluang bagi semua sivitas yang ingin mengakses jurnal elektronik;

- Menampilkan daftar jurnal di halaman awal website Puslata UT;

- Promosi melalui jaringan staf UT yang sedang melakukan penelitian;

- Memasukkan daftar beberapa jurnal elektronik yang dapat diakses dalam buku katalog yang dimiliki tiap mahasiswa. Dalam buku katalog tersebut juga berisikan petunjuk administrasi, cara menggunakan perpustakaan, dan sebagainya; 
- Sosialisasi cara mengakses jurnal elektronik yang disediakan Puslata UT pada saat orientasi studi mahasiswa baru (OSMB).

Selanjutnya, pengembangan koleksi di Puslata UT dapat dijabarkan sebagai berikut.

\subsubsection{Analisis Pengguna}

Kewajiban melayani kebutuhan informasi sivitas akademika UT yang tersebar di beberapa daerah merupakan salah satu alasan Puslata UT mengembangkan koleksi jurnal elektronik. Penyediaan jurnal elektronik yang memiliki keunggulan dapat diakses tanpa batas ruang dan waktu secara cepat merupakan salah satu upaya untuk memenuhi kebutuhan informasi sivitas akademika. Selain itu, Puslata UT juga menganalisis kebutuhan sivitas akademikanya dengan berbagai cara untuk memutuskan penyediaan jurnal elektronik. Cara paling sederhana yang diterapkan Puslata UT adalah melakukan jajak pendapat kepada wakil-wakil sivitas akademika yang ada di lingkungan UT pusat melalui workshop dan mengirimkan surel ke unit-unit yang ada di kampus UT pusat. Cara ini tentunya tidak dapat menjangkau sivitas akademika yang jauh dari UT pusat, tetapi cara ini merupakan cara tercepat dan dianggap mewakili kebutuhan informasi seluruh sivitas akademika termasuk sivitas yang ada di daerah. Hal ini dimungkinkan karena unit-unit yang ada di kampus UT pusat didominasi pengajar yang fungsinya menyampaikan informasi sekaligus membuat rancangan pengajaran kepada sivitas akademika.

Selain itu, mereka dianggap memiliki pengetahuan lebih baik mengenai disiplin ilmu tertentu jika dibandingkan dengan sivitas akademika yang diajarnya. Penawaran sumber informasi lewat surel kepada sivitas akademika di sekitar kampus UT pusat juga dapat diaplikasikan untuk menjangkau sivitas akademika di daerah. Namun, jurnal elektronik yang ditawarkan masih dalam tahap trial dan memiliki batas waktu akses yang relatif singkat sehingga jajak pendapat lewat surel kepada sivitas akademika di daerah perlu direncanakan secara matang.

\subsubsection{Wewenang}

Berdasarkan Buku Pedoman Perpustakaan Perguruan Tinggi (Direktorat Jenderal Pendidikan Tinggi, 2004), kewenangan untuk merumuskan jalannya pengembangan jurnal elektronik di Puslata UT dipercayakan kepada beberapa pihak, yaitu pustakawan, wakil sivitas akademika, dan unit lain yang terkait. Pustakawan Puslata UT sebagai pihak yang mengakomodasi penyedia jurnal elektronik untuk memperkenalkan produknya kepada sivitas akademika. Wakil sivitas akademika menjadi pihak yang memberi pendapat sebagai alat penentu keputusan untuk melanggan jurnal elektronik atau tidak. Selain itu, juga adanya unit lain yang berpotensi memakai jurnal elektronik, antara lain:

a) Lembaga Pengembangan Bahan Ajar, Ujian, dan Sistem Informasi (LPBAUSI);

b) Lembaga Penelitian dan Pengabdian kepada Masyarakat (LPPM);

c) Pusat Jaminan Kualitas (Pusmintas);

d) Pusat Pengembangan Sumber Daya Manusia (PPSDM).

Kewenangan beberapa pihak di atas dengan kapasitasnya masing-masing tentu mempengaruhi kegiatan pengembangan koleksi, salah satunya adalah 
kegiatan seleksi. Tanpa adanya wakil sivitas akademika dari program studi dan unit-unit terkait, pihak Puslata UT tidak akan dapat mengetahui isi informasi yang terkandung di dalam jurnal elektronik dan seberapa pentingnya bagi sivitas akademika. Wakil sivitas akademika dari masing-masing program studi merupakan pihak yang mengetahui kebutuhan informasi sivitas akademikanya dan mengikuti perkembangan informasi mengenai suatu disiplin ilmu. Pustakawan sebagai pengelola Puslata UT merupakan pihak yang bertugas untuk menyediakan jurnal elektronik yang dapat diakses secara cepat, mudah, dan efisien. Kedua belah pihak tersebut melalui dua pendekatan, yaitu pendekatan berdasarkan subjek keilmuan dan jenis format.

\subsubsection{Seleksi}

Wakil sivitas akademika yang memiliki pengetahuan mengenai subjek tertentu dilibatkan dalam proses penyeleksian jurnal elektronik agar dapat memprediksi keterpakaiannya. Setelah wakil sivitas akademika memutuskan jurnal yang akan dilanggan, pustakawan Puslata UT pun melaksanakan keputusan tersebut dengan mempertimbangkan berbagai aspek, antara lain harga langganan jurnal elektronik. Hal ini sudah sewajarnya karena kegiatan Puslata UT lainnya juga membutuhkan dana. Selain itu, kepopuleran dan nama baik penyedia jurnal elektronik juga menjadi pertimbangan dari perwakilan sivitas akademika. Mempertimbangkan nama baik penyedia jurnal elektronik penting karena banyak artikel jurnal elektronik yang beredar tanpa melewati peer review. Padahal fungsi peer review sangat krusial, yaitu melakukan validasi terhadap suatu artikel ilmiah, apakah karya ilmiah tersebut orisinal, metodologi dan sumber datanya tepat, serta menilai kesimpulannya (Mabe, 2006). Banyak perpustakaan telah mengembangkan kebijakan seleksi jurnal elektronik dan prosesnya menggunakan kriteria yang sama, seperti menyeleksi koleksi tercetak (Juznic, 2009).

\subsubsection{Pengadaan Jurnal Elektronik di Puslata UT}

Proses selanjutnya setelah proses mempertimbangkan kebutuhan sivitas akademika,-adalah pengadaan. Pengadaan jurnal elektronik di Puslata UT melalui tiga cara sebagai berikut.

1) Pembelian atau pelangganan

Pembelian atau pelangganan jurnal elektronik membutuhkan biaya yang tidak sedikit dan melewati beberapa proses yang rumit. Cara ini dipilih agar Puslata UT dapat menentukan atau mendapatkan jurnal elektronik yang sesuai kebutuhan sivitas akademika. Pembelian yang dilakukan Puslata UT melalui publisher packages dan aggregator journal. Puslata UT melanggan publisher packages untuk jurnal elektronik dari suatu penerbit yang isinya mencakup beberapa subjek sesuai program studi di UT, yaitu Emerald. Aggregator journal yang dilanggan Puslata UT dianggap memiliki artikel pilihan terbaik dari beberapa penerbit, seperti Gale, Ebsco, dan Proquest. Pengadaan jurnal elektronik di Puslata UT dilaksanakan melalui beberapa siklus kegiatan yang berguna untuk menilai apakah jurnal elektronik yang dilanggan benar-benar digunakan atau dibutuhkan. Siklus tersebut sesuai dengan pendapat Weir (2012) sebagai berikut. 


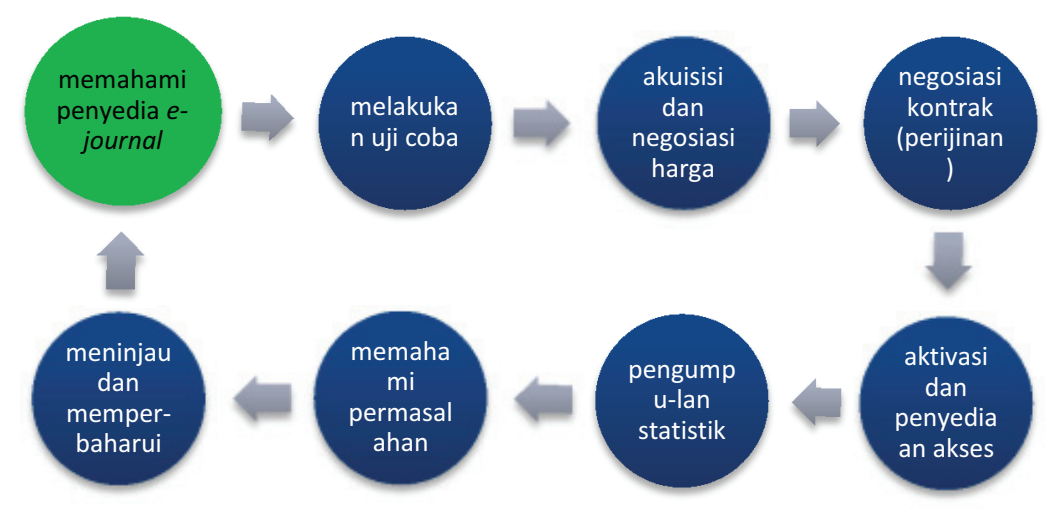

Gambar 1. Siklus melanggan jurnal elektronik (Weir, 2012)

\section{2) Terbitan Perguruan Tinggi}

Selain membeli jurnal elektronik, Puslata UT juga menyediakan jurnal elektronik secara mandiri dengan cara memberikan akses terbuka untuk jurnal elektronik terbitan UT yang sebagaian besar berbahasa Indonesia dengan disiplin ilmu sesuai dengan program studi yang ada di UT. Adapun jurnal elektronik yang aksesnya terbuka tersebut, antara lain Jurnal Pendidikan; Jurnal Internasional; Jurnal Organisasi dan Manajemen; Jurnal Matematika, Sains dan Teknologi; serta Jurnal Pendidikan Terbuka dan Jarak Jauh. Kegiatan diseminasi jurnal terbitan UT dilakukan dengan cara mencantumkan link jurnal elektronik terbitan UT di website Puslata UT. Dengan tersedianya akses ke jurnal elektronik terbitan UT ini, Puslata UT telah menjalankan fungsi deposit sekaligus fungsi diseminasi terbitan UT. Hal ini sesuai dengan yang disebutkan oleh Sulistyo-Basuki (1999) bahwa perpustakaan hendaknya dijadikan pusat penyimpanan semua penerbitan lembaga di perguruan tingginya dan sekaligus sebagai penyalur dari semua penerbitan lembaga itu.

3) Gratis

Penyediaan jurnal elektronik di Puslata UT selain melalui pembelian dan penerbitan sendiri juga menyediakan akses ke artikel jurnal yang gratis. Walaupun cara ini tidak memerlukan biaya untuk penyediaannya, bukan berarti Puslata UT tidak melakukan seleksi. Jurnal elektonik gratis yang disediakan merupakan jurnal yang dapat menguatkan koleksi Puslata UT sekaligus identitas UT sebagai institusi yang mengembangkan sistem pembelajaran jarak jauh. Puslata UT menyediakan link ke jurnal elektronik yang gratis di website. Jurnal elektronik gratis tersebut disediakan oleh organisasi yang berkecimpung dalam pembelajaran jarak jauh. Organisasi tersebut, antara lain Asian Association of Open Universities, International Association for Distance Learning, dan International Council for Open and Distance Education. Adanya sumber informasi terbaru dalam bentuk jurnal elektronik mengenai pembelajaran jarak jauh tentunya sangat bermanfaat bagi UT. Jurnal elektronik tersebut dapat dijadikan rujukan UT dalam mengembangkan kualitas sistem pembelajaran jarak jauh. Tambahan lagi, jurnal elektronik tersebut merupakan hasil penelitian penggiat pendidikan jarak jauh yang berasal dari beberapa negara. 


\subsubsection{Penyiangan}

Johnson (2009), menyatakan bahwa pemilihan sumber informasi dimulai dengan mempertimbangkan komunitas pemustaka dengan misi jangka panjang dan tujuan perpustakaan beserta badan induknya. Puslata UT menyadari hal tersebut, ditunjukkan dengan adanya pemutusan kerja sama dengan penerbit jurnal elektronik Springer. Penyiangan terhadap Springer karena intensitas pemakaiannya oleh sivitas akademika kurang optimal. Puslata UT menganggap anggaran yang untuk melanggan Springer lebih baik dialihkan untuk melanggan jurnal elektronik lain yang memiliki potensi keterpakaian tinggi, seperti Emerald. Dengan keputusan itu, kegiatan penyiangan di Puslata UT telah mempertimbangkan ketersediaan jurnal elektronik atas dasar potensi keterpakaian dan juga biayanya agar dapat digunakan untuk sesuatu yang bermanfaat. Selain itu, ada kegiatan penyiangan di Puslata UT yang bertujuan untuk mempertahankan atau melestarikan jurnal elektronik agar tidak hilang. Ketika masa kerja sama Puslata UT dengan penyedia jurnal elektronik selesai maka Puslata UT tidak lagi dapat mengakses jurnal-jurnal yang berada di pangkalan data online.

Oleh karena itu, Puslata UT melakukan pengarsipan jurnal elektronik secara lokal. Nisonger (1997), memiliki pendapat bahwa penyiangan jurnal elektronik dapat memiliki arti yang berbeda, misalnya keputusan untuk tidak lagi menyediakan akses melalui gropher atau website dan mengarsipkan jurnal elektronik secara lokal. Kegiatan penyimpanan jurnal elektronik secara lokal yang dilakukan Puslata UT karena nilai informasi yang terkandung dalam jurnal elektronik memiliki kemanfaatan jangka panjang. Selain itu, bila jurnal tersebut dicetak dapat berfungsi untuk memenuhi persyaratan akreditasi program studi. Dengan demikian, pengarsipan jurnal elektronik secara lokal selain memiliki nilai informatif juga memiliki nilai ekonomis.

\subsubsection{Evaluasi Koleksi}

Evaluasi koleksi bertujuan menilai hasil guna jurnal elektronik yang dilanggan Puslata UT yang dilakukan pada tengah tahun dan akhir tahun periode berlangganan. Hasil evaluasi terhadap Springer berdampak pada pemutusan kerja sama. Hal ini terjadi karena Springer tidak digunakan oleh sivitas akademika secara optimal. Dalam hal ini, evaluasi yang dilakukan Puslata UT adalah menganalisis jurnal elektronik dengan berfokuskan pengguna, yaitu mengukur keterpakaian koleksi atau seberapa baik kebutuhan pengguna terpenuhi. Evaluasi koleksi penting untuk memberikan penilaian terhadap koleksi yang tersedia, manajemen koleksi ke depannya, penganggaran, pertimbangan format, serta seleksi dan penyiangan sehingga perpustakaan dapat menghindari kegiatan yang tidak efisien dan berisiko (Agee, 2005). Dengan melakukan evaluasi, Puslata UT dapat merencanakan pengadaan, anggaran, dan penyiangan berdasarkan data statistik hasil dari mengukur keterpakaian jurnal elektronik. 


\subsection{Permasalahan Pengembangan Koleksi Jurnal Elektronik di Puslata UT}

Berikut ini beberapa permasalahan yang muncul dalam kegiatan pengembangan koleksi jurnal elektronik di Puslata UT.

1) Cara akses dan pelangganan jurnal elektronik

Pencari informasi membutuhkan usaha ekstra untuk dapat mengakses jurnal elektronik di Puslata UT. Hal ini karena akses ke semua jurnal elektronik yang disediakan Puslata UT tidak terintegrasi menjadi satu kolom pencarian, tetapi perlu membuka masing-masing pangkalan data online. Cara tersebut dianggap merepotkan dan membutuhkan waktu lebih lama untuk mencari artikel tentang subjek tertentu di masing-masing jurnal elektronik. Adanya kerumitan dalam mengakses jurnal elektronik tersebut menandakan perlu adanya pendidikan pengguna dan penyediaan panduan umum maupun spesifik untuk mengakses jurnal elektronik. Kerumitan dalam mengakses jurnal elektronik seperti tersebut di atas akan lebih sederhana dan cepat bila dalam website Puslata UT tersedia satu kotak pencarian yang terintegrasi. Fitur pencarian secara integrasi dianggap terlalu mahal oleh Puslata UT, padahal satu kotak pencarian yang terintegrasi dapat menjadi salah satu sarana untuk menghemat dalam pengadaan jurnal elektronik. Vasishta (2013), menganggap perlu adanya perhatian khusus untuk merancang dan mengembangkan website perpustakaan seperti pentingnya bangunan fisik bagi perpustakaan karena website dapat merupakan sarana publikasi dan diseminasi jurnal elektronik yang ramah bagi pengguna (2013).

Puslata UT telah melanggan jurnal elektronik melalui tiga aggregator dan satu penerbit. Keunggulan aggregator yang menyediakan kumpulan beberapa artikel terbaik dari beberapa penerbit memang terkesan menggiurkan dan menjadi salah satu cara untuk menghemat anggaran. Akan tetapi, bila mengingat Puslata UT melanggan jurnal elektronik melalui tiga pengumpul artikel (aggregator) dari beberapa penerbit maka akan ada kemungkinan munculnya artikel yang sama di ketiga aggregator tersebut. Hal itu tidak akan terjadi pada cara berangganan ke penerbit yang masingmasing memiliki keunggulan subjek tertentu. Dengan adanya kotak pencarian yang terintegrasi Puslata UT akan mendapatkan banyak artikel dengan kemungkinan duplikasi yang minimal.

Puslata UT selama ini melanggan jurnal elektronik dari penyedia dengan fasilitas unlimited user untuk mengantisipasi bila penggunaannya banyak. Akan tetapi, ternyata penggunaannya tidak banyak dan sebagian besar hanya dilakukan di lingkungan kampus UT pusat. Pemilihan unlimited user memang tepat apabila jumlah pengakses jurnal elektronik banyak karena semakin banyak yang mengakses maka harga jurnal elektronik yang disediakan menjadi lebih murah. Namun, penggunaan jurnal elektronik di Puslata UT yang masih sebatas untuk tujuan akreditasi dan hanya digunakan oleh sebagian kecil mahasiswa, pemilihan berlangganan jurnal elektronik secara unlimited user dapat dikatakan kurang tepat. Puslata UT dapat menyediakan jurnal elektronik dengan lebih murah bila hanya membayar jurnal elektronik yang diunduh.

a) Penggunaan jurnal elektronik sedikit

Jumlah pengguna jurnal elektronik pada tahun 2014 hanya sebanyak 11212 (Tabel 1 dan Tabel 2). Rendahnya akses tehadap jurnal elektronik menurut wakil sivitas akademika adalah jurnal elektronik menggunakan bahasa Inggris. Padahal, untuk mengatasi masalah perbedaan bahasa, beberapa penyedia jurnal 
elektronik menyediakan fitur menerjemahkan bahasa. Namun, kualitas terjemahan yang diberikan penyedia jurnal elektronik tidak baik sehingga terlihat berantakan. Sementara itu, Puslata UT memiliki alternatif untuk memenuhi kebutuhan informasi sivitas akademika yang enggan menggunakan jurnal berbahasa asing, yaitu dengan menyediakan jurnal elektronik terbitan UT yang berbahasa Indonesia. Akan tetapi, jurnal elektronik terbitan UT jumlahnya sangat sedikit jika dibandingkan jurnal elektronik berbayar.

Tabel 1. Data Statistik Keterpakaian Proquest

\begin{tabular}{|c|c|c|c|c|}
\hline \multicolumn{5}{|c|}{ Time Frame: JAN-2014 to DEC-2014 } \\
\hline \multicolumn{5}{|c|}{ Account 62722 - Universitas Terbuka Tier (0) } \\
\hline Searches & Database & Cit/Abstract & Any FT Format & Total \\
\hline 354 & ProQuest Nursing \& Allied Health Source & 5 & \begin{tabular}{|l|l|}
32 & 3
\end{tabular} & 37 \\
\hline 354 & ProQuest Deep Indexing: Nursing & 0 & 0 & 0 \\
\hline 354 & ProQuest Nursing \& Allied Health Source & 5 & 32 & 37 \\
\hline 1696 & ProQuest Research Library & 155 & 10927 & 11082 \\
\hline 1680 & ProQuest Research Library: Business & 84 & 10564 & 10648 \\
\hline 1528 & ProQuest Research Library: Health \& Medicine & 2 & 8 & 10 \\
\hline 1528 & ProQuest Research Library: History & 0 & 1 & 1 \\
\hline 1529 & ProQuest Research Library: Literature \& Language & 14 & 159 & 173 \\
\hline 1532 & ProQuest Research Library: Science \& Technology & 16 & 72 & 88 \\
\hline 1539 & ProQuest Research Library: Social Sciences & 39 & 123 & 162 \\
\hline 1528 & ProQuest Research Library: The Arts & 0 & 0 & 0 \\
\hline 527 & ProQuest Agriculture Journals & 7 & 35 & 42 \\
\hline 527 & ProQuest Biology Journals & 3 & 4 & 7 \\
\hline 534 & ProQuest Sociology & 6 & 38 & 44 \\
\hline 558 & ebraryß e-books & 0 & 0 & 0 \\
\hline 13718 & Subtotal & 176 & 11036 & 11212 \\
\hline 13236 & Total Unique Searches & & & \\
\hline
\end{tabular}

Tabel 2. Data Statistik Keterpakaian Gale

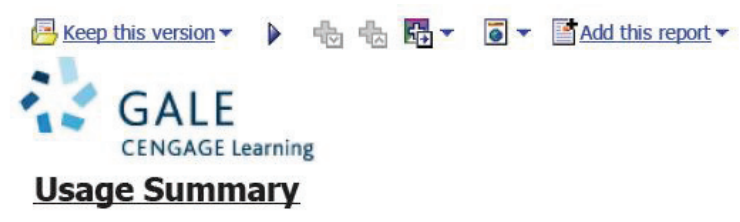

User: admin

Date Selection: Between 01/01/2014 and 12/09/2014 (Date Range) (No data available after 12/05/2014)

Libraries: Universitas Terbuka Indonesia (Location ID: idut)

\begin{tabular}{|l|r|r|r|}
\cline { 2 - 4 } \multicolumn{1}{c|}{} & Inside Usage & Remote Usage & Total Usage \\
\hline Total Sessions & 182 & 10 & 192 \\
\hline Total Connect Time $(\mathrm{min})$ & 2,855 & 67 & 2,922 \\
\hline Average Connect Time $(\mathrm{min})$ & 16 & 7 & 15 \\
\hline Total Fulltext & 292 & 0 & 292 \\
\hline Total Retrievals & 322 & 0 & 322 \\
\hline Total Searches & 704 & 10 & 714 \\
\hline Total Turnaways & 0 & 0 & 0 \\
\hline
\end{tabular}

Selain itu, sistem pendidikan di UT yang tidak mewajibkan sivitas akademikanya membuat tugas akhir berupa karya ilmiah dapat mengurangi kebutuhan akan informasi. Alasan tersebut bukan kewenangan Puslata UT untuk mengubah peraturan agar sivitas akademika menulis suatu karya ilmiah untuk mendapatkan gelar. Akan tetapi, Puslata UT harus memiliki strategi agar sivitas 
akademika memiliki keinginan mengakses sumber informasi, khususnya jurnal elektronik. Misalnya, Puslata UT mengadakan perlombaan penulisan karya ilmiah bagi sivitas akademika dengan minimal menggunakan referensi beberapa artikel dari jurnal elektronik yang dilanggan.

Selain itu, sedikitnya penggunaan jurnal elaktronik juga disebabkan akses internet yang tidak tersebar secara merata di beberapa daerah dan ketidaktahuan sivitas akademika dalam mengakses sumber informasi. Untuk mengatasi masalah ketidaktahuan cara mengakses jurnal elektronik, Puslata UT telah melakukan sosialisasi pendidikan pengguna pada saat OSMB. Adapun masalah tidak ratanya akses internet di beberapa daerah memang benar, namun tidak terlalu signifikan karena daerah yang minim akses internet sekarang jumlahnya tidak banyak.

b) Kegiatan penyiangan kurang maksimal

Jurnal elektronik yang sudah tidak relevan dengan pengguna akan lebih baik bila tidak ditampilkan di laman koleksi e-journal, akan tetapi hal ini belum diterapkan secara maksimal oleh Puslata UT. Nisonger (1997), mengemukakan bahwa penyiangan jurnal elektronik dapat diartikan tidak lagi menyediakan akses melalui gropher atau website dan mengarsipkan jurnal elektronik secara lokal. Masih tercantumnya penyedia jurnal elektronik yang sudah tidak bekerja sama di website Puslata UT dan tidak tercantumnya penyedia baru sebagai penggantinya, menunjukkan kurang maksimalnya perhatian untuk memberikan kemudahan akses. Emerald sebagai penyedia baru belum tercantum dalam laman koleksi e-journal, sedangkan Springer yang sudah tidak bekerja sama masih ada (Gambar 2). Padahal menurut Lehman (2013), beberapa tujuan diadakannya penyiangan adalah membuat koleksi lebih dapat dimanfaatkan sebagai sumber informasi yang akurat, relevan, up to date, serta menarik dan memberikan kemudahan bagi pemakai.

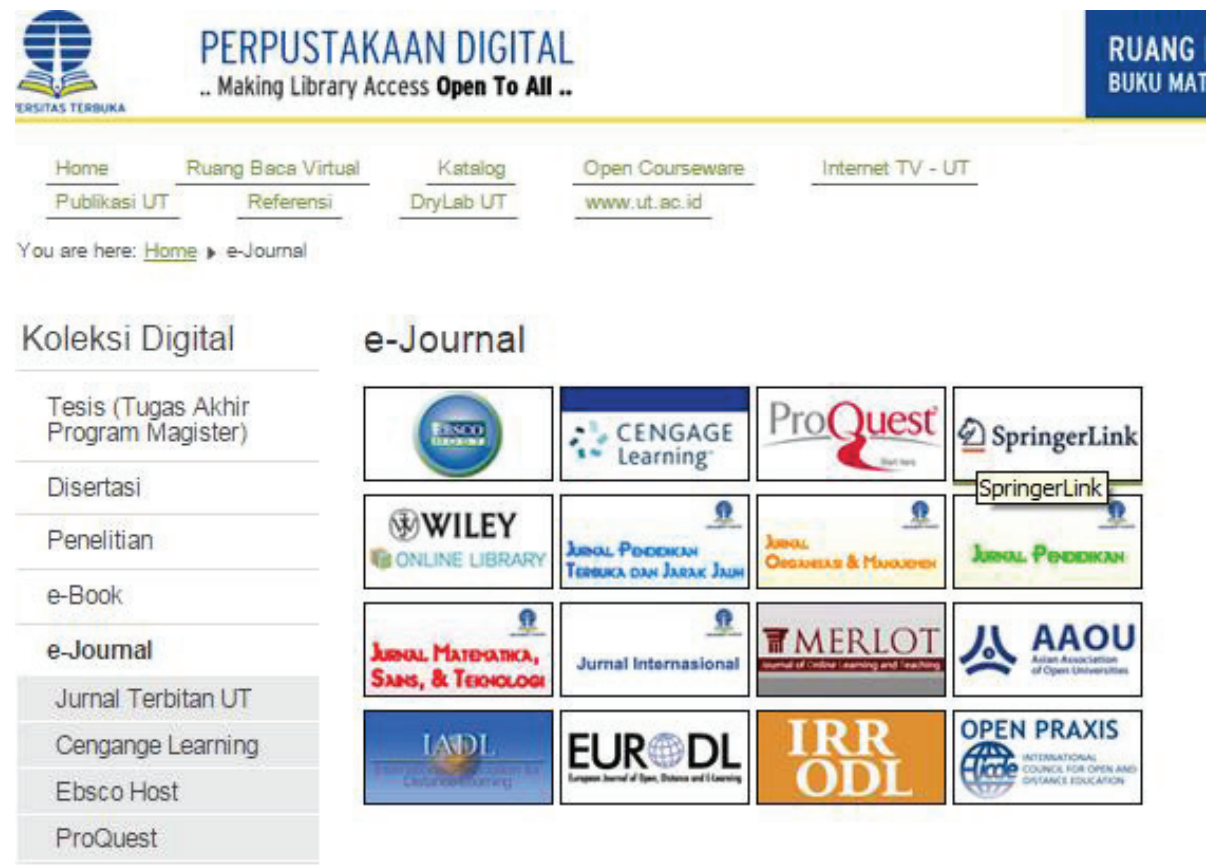

Gambar 2. Laman koleksi E-Journal Puslata UT 
Staf Puslata UT perlu secara periodik mengecek kondisi jurnal elektroniknya sebagai bentuk komitmen perpustakaan untuk menyediakan akses yang mudah bagi pemustaka. Hasil kegiatan tersebut kemudian didokumentasikan sebagai laporan. Zhang (2003), berpendapat ada dua laporan yang penting sebagai bahan evaluasi dan dasar penyiangan, yaitu:

a) Laporan Pemeriksaan Konten Elektronik: mendata URL yang dicek, memeriksa URL yang bekerja dan yang tidak bekerja, tanggal pemeriksaan, konfirmasi ulang, rentang waktu, nama penyedia, dan memberikan inisial pada masing-masing data.

b) Laporan Identifikasi dan Penanganan Masalah: mencatat konten yang bermasalah, tanggal masalah dilaporkan, deskripsi masalah, orang yang melaporkan masalah, tindakan yang diambil, hasil, tanggal masalah diselesaikan, dan komentar.

\section{KESIMPULAN}

Rangkaian kegiatan pengembangan koleksi jurnal elektronik yang dilakukan Puslata UT dalam rangka menyediakan jurnal elektronik sesuai dengan tujuan perguruan tinggi, khususnya UT. Akan tetapi, pemanfaatan jurnal elektronik di Puslata UT pada tahun 2014/2015 sangat rendah. Hal tersebut disebabkan: a) akses ke jurnal elektronik Puslata UT membingungkan sehingga memungkinkan banyak sivitas akademika gagal paham menggunakannya; b) peraturan UT tidak mendorong sivitas akademika membuat karya ilmiah yang merujuk terbitan ilmiah; dan c) belum siapnya sivitas akademika menerima informasi dari terbitan internasional. Adapun saran kajian ini, yaitu: a) Puslata UT harus memiliki panduan tertulis yang khusus dalam pengembangan koleksi jurnal elektronik agar kegiatan terkait seperti penyiangan jurnal elektronik memiliki manfaat yang tinggi; dan b) perlu adanya koordinasi antara pengelola website dan bagian pengadaan Puslata UT yang diketahui pimpinan Puslata UT dan terdokumentasi agar memunculkan rasa tanggung jawab dari pihak yang terkait. Dengan demikian, kejadian pencantuman jurnal elektronik yang sudah tidak dilanggan dan tidak dicantumkannya jurnal elektronik yang dilanggan di website dapat dihindari.

Mengenai sedikitnya pengakses jurnal elektronik, Puslata UT harus dapat mengembangkan kegiatan promosi yang efektif untuk merangsang penggunaan jurnal elektronik. Pengembangan kegiatan promosi yang sudah dilakukan oleh Puslata UT dapat dilanjutkan dengan mengembangkan kerja sama yang terstruktur antarunit di Universitas Terbuka untuk saling mendukung dalam menyusun kegiatan pembelajaran. Salah satu contoh kerja sama tersebut adalah pihak pengajar melaporkan rencana pengajarannya kepada Puslata UT, kemudian Puslata UT menyediakan beberapa link akses ke artikel-artikel yang berkaitan dengan rencana pengajaran. Selanjutnya, pengajar akan mewajibkan mahasiswanya untuk membaca atau menerjemahkan artikel-artikel yang dianjurkan. Selain itu, Puslata UT juga dapat membuat semacam bibliografi tentang artikel yang membahas tentang tema materi yang diajarkan pengajar. Dengan menyediakan bibliografi tersebut diharapkan mahasiswa terdorong untuk mencoba mengakses jurnal elektronik. Jurnal elektronik yang disediakan Puslata UT dapat diakses melalui internet bagi sivitas akademika yang berdomisili jauh dari gedung UT pusat. Akan tetapi, penyebaran teknologi informasi dan komunikasi di beberapa daerah belum merata sehingga akses untuk membaca jurnal elektronik menjadi beban tersendiri. Untuk mengatasi masalah tersebut, Puslata UT disarankan untuk menyediakan akses offline untuk jurnal elektronik terbitan UT dengan cara mengirimkan CD-ROM ke Unit Program Belajar 
Jarak Jauh UT (UPBJJ-UT) yang ada di daerah. Akan tetapi, hal ini tidak berlaku untuk jurnal elektronik yang dilanggan karena melanggar kontrak dengan provider dan dapat mengakibatkan kerugian bagi Puslata UT. Selain itu, dapat dengan menyediakan sarana dan prasarana seperti menyediakan komputer atau gadget serta penambahan bandwidth di UPBJJ-UT.

\section{DAFTAR PUSTAKA}

Agee, Jim. 2005. Collection Evaluation: a Foundation for Collection Development. Collection Building, 24 (3), 92-95.

Badan Standardisasi Nasional. 2009. Standar Nasional Indonesia: Perpustakaan Perguruan Tinggi. February 15, 2015. Jakarta.

Dhingra, Navjyoti dan Vasishta, Seema. 2007. E-Journals: Problem or Panacea for Higher Education?. Chandigarh. (https://www.researchgate.net/publication/28810552_Ejournals_problem_or_panacea_for_higher_education).

Direktorat Jenderal Pendidikan Tinggi, Depdiknas. 2004. Perpustakaan Perguruan Tinggi: Buku Pedoman. Jakarta: Ditjen-Dikti, Depdiknas.

Disher, Wayne. 2007. Crash Course in Collection Development. Westport: Libraries Unlimited.

Johnson, Peggy. 2009. Fundamental of Collection Development and Management ( $2^{\text {nd }}$ ed.). United States: American Library Association.

Juznic, Primoz. 2009. Using a Decision Grid Process to Evaluate Library Collection and E-Journals. New Library World, Vol. 110 (7/8), 341-356.

King \& Tenopir. 2004. Scholarly Journal and Digital Database Pricing: Threat or Opportunity. Chapter 3 in Jeffrey Mackie-Manson, ed. Cambridge, MA: MIT Press. (http://web.utk.edu/ tenopir/eprints/database_pricing.pdf).

Koontz, Christie and Gubbin, Barbara. 2010. IFLA Public Library Service Guidelines. Berlin: De Gruyter Saur.

Lehman, Kathleen A. 2014. Collection Development and Management: an Overview of the Literature, 2011-12. Library Resources \& Technical Services, 58 (3). 169-177.

Mabe, Michael. 2006. Electronic Journal Publishing. The E-Resources Management Handbook, 9(2). 56-66.

Moedjono, Parlinah. 1979. Pedoman Umum Perpustakaan Perguruan Tinggi. Jakarta: Ditjen-Dikti, Depdikbud.

Nawawi, Hadari. 1992. Instrumen Penelitian Bidang Sosial. Yogyakarta: Gadjah Mada University Press.

Nisonger, Thomas E. 1997. Electronic Journal Collection Issues. Collection Building, 16(2), 58-65.

Pendit, Putu Laxman. 2008. Perpustakaan Digital, dari A sampai Z. Jakarta: Cita Karyakarsa Mandiri.

Pollet, Miriam. 1982. Criteria for Science Book Selection in Academic Libraries. Collection Building, 4(3), 42-47. 
Sulistyo-Basuki. 1994. Pengantar Ilmu Perpustakaan dan Informasi. Jakarta: Gramedia Pustaka Utama.

Vasishta, Seema. 2013. Dissemination of Electronic Journals. The Electronic Library, 31(3), 278289.

Weir, Ryan O. 2012. LITA Guide: Managing Electronic Resources. Chicago: American Library Association.

Wusteman, Judith. 1996. Electronic Journal Formats. March 15, 2015. Technical Report. University of Kent, Canterbury. (https://kar.kent.ac.uk/21377/1/EjournalSmith.pdf).

Zhang, Xiaoyin. 2003. Combining Traditional Journal Check-in and Claiming activities with Electronic Journal Initiation and Maintenance Activities. Library Resources \& Technical Services, 47(4), 208-214. 